\title{
A secondary analysis of FDG spatio-temporal consistency in the randomized phase II PET-boost trial in stage II-III NSCLC
}

Citation for published version (APA):

La Fontaine, M., Vogel, W., van Diessen, J., van Elmpt, W., Reymen, B., Persson, G., Westman, G., De Ruysscher, D., Belderbos, J., \& Sonke, J-J. (2018). A secondary analysis of FDG spatio-temporal consistency in the randomized phase II PET-boost trial in stage II-III NSCLC. Radiotherapy and Oncology, 127(2), 259-266. https://doi.org/10.1016/j.radonc.2018.03.020

Document status and date:

Published: 01/05/2018

DOI:

10.1016/j.radonc.2018.03.020

Document Version:

Publisher's PDF, also known as Version of record

\section{Document license:}

Taverne

Please check the document version of this publication:

- A submitted manuscript is the version of the article upon submission and before peer-review. There can be important differences between the submitted version and the official published version of record.

People interested in the research are advised to contact the author for the final version of the publication, or visit the DOI to the publisher's website.

- The final author version and the galley proof are versions of the publication after peer review.

- The final published version features the final layout of the paper including the volume, issue and page numbers.

Link to publication

\footnotetext{
General rights rights.

- You may freely distribute the URL identifying the publication in the public portal. please follow below link for the End User Agreement:

www.umlib.nl/taverne-license

Take down policy

If you believe that this document breaches copyright please contact us at:

repository@maastrichtuniversity.nl

providing details and we will investigate your claim.
}

Copyright and moral rights for the publications made accessible in the public portal are retained by the authors and/or other copyright owners and it is a condition of accessing publications that users recognise and abide by the legal requirements associated with these

- Users may download and print one copy of any publication from the public portal for the purpose of private study or research.

- You may not further distribute the material or use it for any profit-making activity or commercial gain

If the publication is distributed under the terms of Article $25 \mathrm{fa}$ of the Dutch Copyright Act, indicated by the "Taverne" license above, 
Phase II randomised trial

\title{
A secondary analysis of FDG spatio-temporal consistency in the randomized phase II PET-boost trial in stage II-III NSCLC
}

\author{
Matthew La Fontaine ${ }^{\mathrm{a}}$, Wouter Vogel ${ }^{\mathrm{a}}$, Judi van Diessen ${ }^{\mathrm{a}}$, Wouter van Elmpt ${ }^{\mathrm{b}}$, Bart Reymen ${ }^{\mathrm{b}}$, \\ Gitte Persson ${ }^{\mathrm{d}}$, Gunnar Westman ${ }^{\mathrm{d}}$, Dirk De Ruysscher ${ }^{\mathrm{b}, \mathrm{c}}$, José Belderbos ${ }^{\mathrm{a}}$, Jan-Jakob Sonke ${ }^{\mathrm{a}, *}$

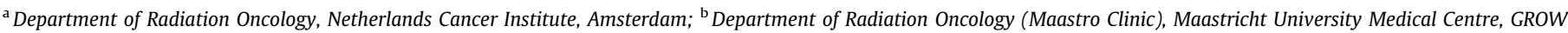

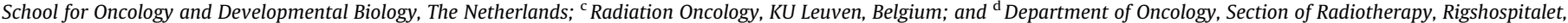 \\ Copenhagen University Hospital, Denmark
}

\section{A R T I C L E I N F O}

\section{Article history:}

Received 1 June 2017

Received in revised form 14 March 2018

Accepted 15 March 2018

Available online 27 April 2018

\section{Keywords:}

FDG PET

Dose painting

NSCLC

Dose escalation

Integrated boost

\begin{abstract}
A B S T R A C T
Purpose: FDG-PET scans have shown spatial consistency in NSCLC patients before and following chemoradiotherapy, implying radioresistance. We hypothesized that patients, who received FDG-PET redistributed dose painting, would demonstrate reduced spatial consistency when compared to registered patients or to escalated dose treatment.

Methods: Stage II-IIIB, inoperable NSCLC patients were randomized in a phase II trial (NCT01024829) to (chemo)radiotherapy of either homogeneous boosting to the primary tumor, or redistributed inhomogeneous boosting to the GTV subvolume (FDG-SUV $>50 \% \mathrm{SUV}_{\max }$ ). Patients who could not be boosted ( $\geq 72$ $\mathrm{Gy})$ received $66 \mathrm{~Gy}$ in 24 fractions. Spatial consistency of pre-treatment and post-treatment ( 3 months) FDG-PET scans was measured by various overlap fraction thresholds.

Results: $66 / 82$ patients analyzed received randomized treatment in the trial. Thresholds of $50 \% \mathrm{SUV}_{\max }$ pre-treatment and $70 \% \mathrm{SUV}_{\max }$ post-treatment yielded a median overlap fraction of 0.63 [interquartile range: $0.15-0.93$ ], with similar results for other thresholds. No significant differences were found among overlap fractions of the treatment groups. A high incidence of FDG-uptake in normal lung (grade-1 pneumonitis: 73\%) was found post-treatment.

Conclusion: FDG redistributed boosting did not reduce FDG spatial consistency from pre-treatment to post-treatment, which was highly variable among patients. The study found high numbers of patients with lung inflammation after treatment.
\end{abstract}

(C) 2018 Elsevier B.V. All rights reserved. Radiotherapy and Oncology 127 (2018) 259-266
Patients with non-small cell lung cancer (NSCLC) have shown poor local-regional progression free and overall survival, where an improvement of local control has been associated with an increase in overall survival [1-3]. As the primary tumor is the dominant location of failure, boosting strategies might be favorable [4]. While dose escalation has shown promise in phase I-II trials, it was detrimental in a randomized phase III trial $[5,6]$. Although homogeneous dose escalation may be limited by nearby organs at risk, dose painting may be a solution to higher local control rates with limited increase in normal tissue toxicity [7-10]. Imaging and treatment for dose painting, where higher dose levels are delivered to radio-resistant subvolumes of the tumor, have been a focus in several studies of NSCLC patients [11-15].

\footnotetext{
* Corresponding author at: Plesmanlaan 121, 1066 CX Amsterdam, The Netherlands.

E-mail addresses: m.l.fontaine@nki.nl (M. La Fontaine), j.sonke@nki.nl (J.-J. Sonke).
}

Of available imaging biomarkers, ${ }^{18} \mathrm{~F}$-Fluorodeoxsyglucose (FDG), a surrogate for metabolic activity, is a prime target for dose escalation in NSCLC patients $[14,15]$. FDG has been a widely available tracer with an established imaging and analysis protocol [16]. Pre-treatment FDG-PET imaging metrics (e.g. SUV $\mathrm{S}_{\max }$ ) have shown to be prognostic for both survival and local control [17-19]. Pre- and 3-months post-treatment FDG-PET imaging have demonstrated spatially consistent high uptake regions in non-responders, implying treatment resistance in high uptake areas, and providing potential dose redistribution regions within the tumor [15]. In addition, the pre-treatment FDG avid areas (surrogate for radioresistance) may be spatially consistent throughout the course of treatment; therefore, potentially not causing with an increase in adaptive replanning requirements in a dose painting trial targeting the high uptake regions [20].

From the conclusions of these studies, a multi-institutional trial (PET-boost trial; ClinicalTrial.gov identifier: NCT01024829) was initiated to improve local control of NSCLC patients. The trial was 
an international, randomized phase II trial, where patients received concomitant or sequential chemoradiotherapy or radiotherapy alone with either a homogenous boost to the primary tumor $(\operatorname{Arm} \mathrm{A})$ or an inhomogeneous boost (Arm B) to the FDG avid areas $\left(>50 \% \mathrm{SUV}_{\max }\right)[14]$. The remaining part of the tumor in Arm B and the involved lymph nodes were planned to receive $66 \mathrm{~Gy}$ in 24 fractions. Patients, who signed informed consent, where the primary tumor could not be escalated ( $\geq 72 \mathrm{~Gy}$ ), were designated as registered patients (REG) and received $66 \mathrm{~Gy}$ in 24 fractions. The primary endpoint of this trial was local progression free survival at 1 year. The secondary endpoints were acute and late toxicity, overall survival, and quality of life.

In the present work, we followed the analysis methodology of Aerts et al. [15] in the PET-boost trial. We hypothesized that the non-randomized group of patients (no boost) maintains a high consistency between pre- and post-treatment FDG-PET as seen in Aerts et al. [15]. In addition, the patients who received a homogeneous boost would have higher spatial consistency than patients who received an inhomogeneous boost. Furthermore, we hypothesized that fewer randomized patients would have residual FDGPET uptake when compared to the non-randomized group (REG).

Thus, the purpose of this planned secondary analysis was to investigate if inhomogeneous dose boosting reduced posttreatment FDG uptake and the spatial stability of the high FDG uptake tumor regions 3-month post-treatment.

\section{Materials and methods}

\section{Trial and treatment}

From April 2010 through November 2016, 136 NSCLC patients gave informed consent to participate in an IRB approved study. These patients were imaged and treated in the multicenter, randomized phase II PET-boost trial (closed November 2017) with the primary aim of improving local control. The trial required a minimum tumor diameter $(\geq 4 \mathrm{~cm})$ and a minimum $\operatorname{SUV}_{\max }(\geq 5)$ to allow tumor dose escalation. Patients were excluded if they had prior radiotherapy to the thorax, distant metastases or tumor growth into large vessels. All patients received daily radiotherapy for 24 fractions. Treatment allowed for a combination with either concurrent or sequential chemotherapy in the presence of stage III disease. The chemotherapy regimen varied according to site. The concurrent chemo-radiotherapy regimen consisted of Cisplatin-Etoposide, Cisplatin-Vinorelbin, or daily dose Cisplatin. Carboplatin instead of Cisplatin was incidentally applied. Patients may have received one course of chemotherapy followed by concurrent chemo-radiotherapy or two cycles of induction chemotherapy (any type) followed by radiation. Dose escalation was pursued until either normal tissue tolerances were met, or until a dose of up to $5.4 \mathrm{~Gy}$ per fraction was reached (129.6 Gy in 24 fractions). The gross tumor volume of the primary tumor (GTV) was delineated on a mid-ventilation planning CT. Planned tumor volume (PTV) margins varied according to institutional policies. In the case of nearby organs at risk for the PTV, a $15 \%$ reduction of volume of the PTV was allowed. For each randomized patient, a treatment plan (IMRT or VMAT) for both arms was made with the Mean Lung Dose (MLD) being within 0.5 Gy of one another, effectively normalizing the mean PTV dose [14]. This led to the homogeneously escalated dose in Arm A to be redistributed in Arm B from the FDG cold to the FDG hot spots of the primary tumor GTV. Treatment consisted of step-and-shoot IMRT with an integrated boost, where 5-7 co-planar beams of $10 \mathrm{MV}$ were applied. Previously published work provides details on the specifics of the trial, target and tissue volume definitions, treatment planning, prescribed dose, and constraints for the organs at risk [14].

\section{Imaging analysis}

Patients received a pre-treatment FDG-PET scan according to the NEDPAS protocol or EANM guidelines within 4 weeks of the beginning of treatment, and a follow-up FDG-PET/CT scan scheduled 3-months post-treatment [16]. Patients undergoing sequential chemoradiotherapy were required to have a new pretreatment PET scan after chemotherapy, which was used in this analysis. Patients received a PET/CT scan after approximately 60 min of uptake time. All patient data were sent to a central location for analysis (NKI). For FDG PET analysis, the standardized uptake value (SUV) was defined as the measured activity $(\mathrm{MBq} / \mathrm{mL})$ normalized by the ratio of the injected activity (MBq) over the bodyweight $(\mathrm{kg})$. The corresponding CT scans of the pre-treatment and post-treatment FDG-PET scans were rigidly registered to the planning CT using in-house software (WorldMatch). In the case of the planning CT being also the pre-treatment CT scan of the FDG-PET scan, only the post-treatment CT scan was registered to the planning CT. Tumors connected to the rib cage were registered according to a bony anatomy match, while tumors connected to the mediastinum were registered to the carina. Tumors not attached to either, were registered without rotations using a mask of the tumor. Registrations were visually verified by an independent observer (radiation oncologist), where discrepancies were resolved with a consensus between observers. The same procedure was used even for post-treatment scans demonstrating tumor regression as the rigid registration attempted to mimic the work of Aerts et al. [15].

We applied the analysis as presented by Aerts et al. [15], using the aorta $S_{U V} V_{\max }$ to threshold background activity in the tumor post-treatment FDG PET scan, which was used to identify metabolic responders [15,21]. Due to the escalated treatment doses, there was a possibility of normal tissue uptake in the GTV as well as non-disease related inflammation at the 3 month posttreatment FDG-PET scan in the lung. For each patient, a nuclear medicine physician (W. Vogel) contoured out non-disease related tissue uptake in the lung (normal tissue, inflammation) using a visual inspection of differences found from pre-treatment to post-treatment HU on the CT scans and their corresponding FDG PET scans. Found differences in normal tissue uptake that extended within the GTV contour were excluded from analysis, where physician uncertainty in a tissue between normal tissue and tumor inside the GTV resulted in tissue classification as tumor. Patients with marked post-treatment FDG PET uptake (above aorta SUV $_{\max }$ ) and changes in HU from pre-treatment to post-treatment CT scans were noted as having grade 1 radiation induced pneumonitis.

The overlap fraction of high uptake FDG regions from pretreatment to post-treatment scans was used to evaluate spatial consistency of FDG-uptake [15,22]. The overlap fraction was defined as the intersecting volume divided by the smallest volume. The intersecting volume was determined by comparing a posttreatment tumor volume of a specific PET threshold (SUV $\mathrm{Sax}_{\text {: }}$ $70 \%, 80 \%$, and $90 \%$, SUV: $2.5,5.0$ ) to $50 \%$ of $S_{\text {max }}$ of the pretreatment tumor volume. The intersecting volume was then normalized by the smaller of the two intersecting volumes, coinciding with the post-treatment volume for all, but five patients analyzed. The PET threshold used for pre-treatment $\left(50 \% \mathrm{SUV}_{\max }\right)$ was determined by the boosted volume of the primary tumor in Arm B, as well as the recommended choice as determined by a sensitivity study of various overlap fractions of Aerts et al. [15].

\section{Statistical analysis}

The overlap fraction was calculated for each treatment group. Mann-Whitney U tests were used to determine if there was a difference in overlap fractions, tumor SUV, and tumor volume 
between groups. Significant differences between treatment groups were determined with an $\alpha$ of 0.05 . All reported values are given in mean \pm standard deviation, unless stated otherwise.

\section{Results}

At the time of analysis (November 2016), data from 82 patients were prepared for evaluation, having completed both pre- and post-treatment FDG-PET scans, of which 79 were analyzed. The three patients excluded from analysis either had severe tumor deformations hindering registration $(n=1)$, or exhibited extremely low SUV in normal tissue on the post-treatment scan (e. g. liver $<0$. 5 SUV), questioning the validity of SUV in other tissues $(n=2)$. Within this sub-study, 29 patients were treated in Arm A (homogeneous boost), 35 patients were in Arm B (inhomogeneous boost), and 15 patients were in the REG group. A summary of patient characteristics can be found in Table 1. The pre-treatment $S_{\text {UVax }}$ among treatment groups was $14.4 \pm 5.6$ for Arm A, $15.2 \pm 6.8$ for Arm B, and $18.2 \pm 7.9$ for the REG. Primary tumor volume and $\mathrm{SUV}_{\max }$ for pre-treatment values were not significantly different between the boosted treatment arms $(p=0.80, p=0.614)$, or between the boosted arms and the REG group $(p=0.096$, $\mathrm{p}=0.074$ ). All treatment groups experienced a marked decrease in $\mathrm{SUV}_{\max }$ with post-treatment values of $5.1 \pm 2.5$ for Arm A, $4.2 \pm 1.6$ for Arm B, and $5.5 \pm 3.8$ for the REG.

The aorta SUV max $_{\text {was }}$ waccessfully extracted from all scans with a mean study population $S_{U} V_{\max }$ of $2.6 \pm 0.5$. As shown in Table 1 , aorta $S_{U V}$ max was consistent between treatment arms, and between pre-treatment and post-treatment values. The posttreatment primary GTV SUV max $_{\max }$ of all patients (excluding nondisease uptake as determined by physicians) was $4.8 \pm 2.5$, which was lower than the pre-treatment PET SUV, with an average PET relative response (normalized to pre-treatment SUV) of at least $60 \%$ in all treatment groups (Table 1). The post-treatment GTV $\mathrm{SUV}_{\text {max }}$ was consistently higher than the aorta $\mathrm{SUV}_{\max }$ for all patients analyzed, except two (Fig. 1a). Patients $(n=6)$, where physicians determined the residual uptake inside the GTV was not disease related were excluded from the comparison between the post-treatment $\mathrm{SUV}_{\max }$ of the aorta and the GTV.

The overlap fractions were similar among the treatment groups with a large dispersion among the study population. A sample patient with a high overlap fraction (a,b), and a patient with a low overlap fraction (c,d) are illustrated in Fig. 2. The distribution of overlap fractions among treatment groups and within group is displayed in Fig. 3. The study population overlap fraction of $50 \%$ pre-treatment $\mathrm{SUV}_{\max }$ and post-treatment region of $70 \% \mathrm{SUV}_{\max }$ yielded a median overlap fraction of 0.63 overall patients, and values of 0.77 (Arm A), 0.64 (Arm B), and 0.45 (REG). These values ranged from 0 to 1 with a large spread over all patients with the interquartile range from 0.15 to 0.93 . Similar trends were observed for the other applied thresholds to the overlap fractions (Fig. 3). No significant differences $(p>0.05)$ were found among the treatment groups, or between the boosted treatment groups (Arm A, Arm B) and the REG, with p-values ranging from 0.09 to 0.76 (Table 2). The results for the fixed threshold of 5.0 SUV were excluded as only 21 patients achieved this post-treatment SUV, leading to small patient numbers in treatment groups of Arm A (10), Arm B (6), and REG (5).

There was a high incidence of (chemo)radiation induced normal tissue activity in the post-treatment FDG-PET scans. In approximately $50 \%$ of patients, a nuclear medicine physician corrected for nearby normal tissue spillover into the tumor volume resulting from either the heart ( 2 cases), the liver ( 2 cases), nearby lymphnodes ( 4 cases), ribs ( 1 case) or lung parenchyma inflammation (30 cases). Although the total incidence of lung inflammation, including cases both affecting and not affecting analysis, was high (60 cases), it was independent of treatment arm with rates of $72 \%$ (Arm A), 74\% (Arm B), and 73\% (REG). The mean inflammation SUV over all patients was $4.9 \pm 2.1$, comparable to the posttreatment tumor $\mathrm{SUV}_{\max }$ of $4.8 \pm 2.5$, but higher than the aorta

Table 1

Patient characteristics of treatment groups.

\begin{tabular}{|c|c|c|c|c|}
\hline \multirow[t]{2}{*}{ Patient Characteristics } & & \multicolumn{3}{|c|}{ Treatment Groups } \\
\hline & & $\operatorname{Arm} \mathrm{A}$ & Arm B & REG \\
\hline No. Patients & & 29 & 35 & 15 \\
\hline Sex & $\begin{array}{l}\text { Male } \\
\text { Female }\end{array}$ & $\begin{array}{c}\mathrm{n}=22 \\
7\end{array}$ & $\begin{array}{c}\mathrm{n}=14 \\
21\end{array}$ & $\begin{array}{c}\mathrm{n}=10 \\
5\end{array}$ \\
\hline Tumor Stage & $\begin{array}{l}\text { II } \\
\text { III }\end{array}$ & $\begin{array}{c}\mathrm{n}=4 \\
25\end{array}$ & $\begin{array}{c}\mathrm{n}=4 \\
31\end{array}$ & $\begin{array}{c}n=2 \\
13\end{array}$ \\
\hline Histology & $\begin{array}{l}\text { Squamous c.c. } \\
\text { Adenocarcinoma } \\
\text { Large c.c. } \\
\text { Non-squamous c.c. }\end{array}$ & $\begin{array}{c}n=9 \\
9 \\
4 \\
7\end{array}$ & $\begin{array}{c}\mathrm{n}=15 \\
9 \\
6 \\
5\end{array}$ & $\begin{array}{c}n=7 \\
4 \\
1 \\
3\end{array}$ \\
\hline Pre-treatment & $\begin{array}{l}\text { SUV }_{\max } \\
\text { GTV met vol. (cc)* } \\
\text { Aorta SUV } \\
\text { max }\end{array}$ & $\begin{array}{c}14.4 \pm 5.6 \\
85.8[9.2-249.5] \\
2.5 \pm 0.4\end{array}$ & $\begin{array}{c}15.2 \pm 6.8 \\
74.6[20.8-808.2] \\
2.5 \pm 0.4\end{array}$ & $\begin{array}{c}18.2 \pm 7.9 \\
158.8[13.0-398.2] \\
2.9 \pm 0.7\end{array}$ \\
\hline Post-Treatment & $\begin{array}{l}\text { SUV }_{\max } \\
\text { GTV met vol. (cc) } \\
\text { Aorta SUV } \\
\text { PET response (\%) } \\
\text { Inflammation (\%) }\end{array}$ & $\begin{array}{c}5.1 \pm 2.5 \\
13.0[0.0-98.6] \\
2.6 \pm 0.5 \\
-60.0 \pm 36.0 \\
72\end{array}$ & $\begin{array}{c}4.2 \pm 1.6 \\
2.4[0.0-170.6] \\
2.5 \pm 0.5 \\
-72.9 \pm 16.8 \\
74\end{array}$ & $\begin{array}{c}5.5 \pm 3.8 \\
6.6[0.0-301.4] \\
2.6 \pm 0.5 \\
-64.2 \pm 24.8 \\
73\end{array}$ \\
\hline PTV & $\begin{array}{l}\text { Volume (cc) } \\
\text { Mean dose }\end{array}$ & $\begin{array}{c}400[219-707] \\
76.1[69.1-108.6]\end{array}$ & $\begin{array}{c}330[129-1593] \\
75.6[69.9-118.8]\end{array}$ & $\begin{array}{l}518[249-1348] \\
65.2[49.5-66.1]\end{array}$ \\
\hline Chemotherapy & $\begin{array}{l}\text { Sequential } \\
\text { Concurrent } \\
\text { None }\end{array}$ & $\begin{array}{c}n=1 \\
21 \\
7\end{array}$ & $\begin{array}{c}\mathrm{n}=4 \\
23 \\
8\end{array}$ & $\begin{array}{c}n=0 \\
10 \\
5\end{array}$ \\
\hline
\end{tabular}

Abbreviation: For tumor histology, c.c. refers to cell carcinoma.

"GTV metabolic volume is defined using the aorta $\mathrm{SUV}_{\max }$ and reported as median [range].

$\dagger$ Percentage of patients with apparent grade 1 or higher pneumonitis. 

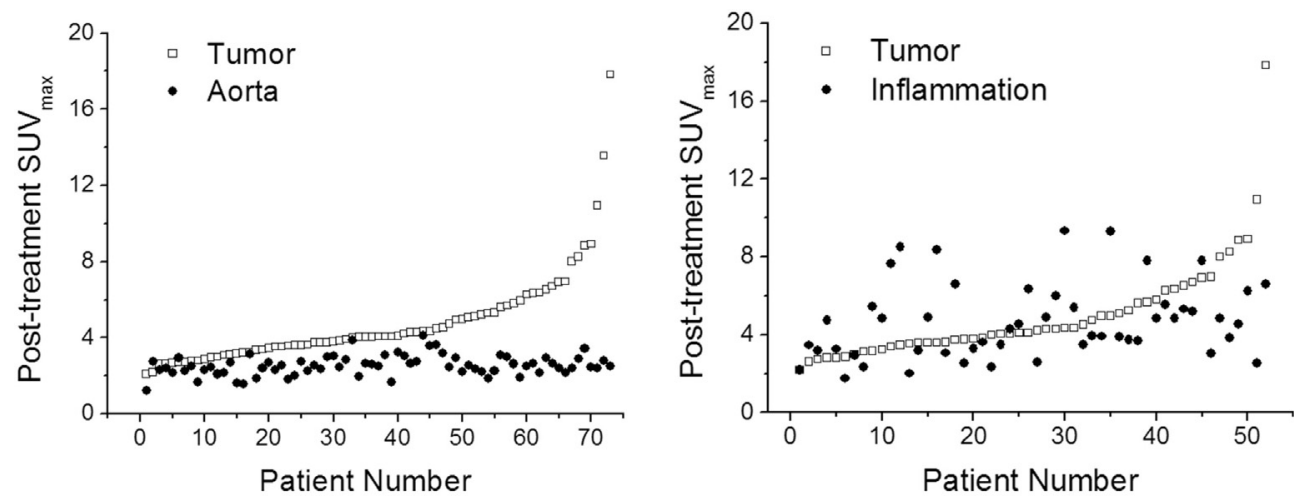

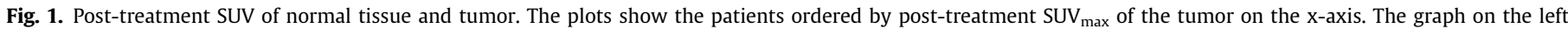

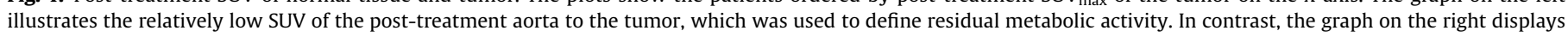
the SUV ${ }_{\max }$ for patients with inflammation (pneumonitis), having high SUV $\mathrm{max}_{\operatorname{man}}$ in comparison to the tumor values.

values (Fig. 1). A sample patient demonstrating high inflammation is found in Fig. 2 (e,f).

\section{Discussion}

This study investigated the spatial consistency between pretreatment and post-treatment FDG-PET avid areas in NSCLC patients, who underwent integrated boosting regimes until individual normal tissue constraints were met. All of the initial hypotheses were found to be not true in the study. The nonrandomized group did not maintain high FDG spatial consistency, or did it have a significantly greater percentage of patients with residual FDG-PET uptake than the randomized patients. In addition, boosting homogenously did not have significantly higher FDG spatial consistency than inhomogeneous boosting.

The non-randomized patients of the REG group could not reproduce the high overlap fractions $(>0.70)$ found in a previous study by Aerts et al. [15]. As we adopted a similar methodology to this study and its validation study, we expected to be able to reproduce the high overlap fractions in our REG group [12,15], but this was not the case. The overlap fraction medians of $0.45,0.36,0.10$ for the post-treatment thresholds of $70 \%, 80 \%$, and $90 \% \mathrm{SUV}_{\max }$ actually showed the opposite trend of decreasing overlap fraction with increasing post-treatment threshold [15]. One of possible explanations could be due to use of concurrent chemoradiotherapy in the PET-boost trial (68\%), instead of sequential (Aerts et al.: 80\%) [15]. Sequential chemoradiotherapy may potentially "preselect" the tumor prior to radiotherapy by eliminating less resistant cells. Such an effect would lead to higher overlap fractions in sequential as opposed to concurrent chemoradiotherapy regimes. There was some support for this explanation as greater tumor reduction was seen in the PET-boost trial, implying more resistant tumors at the time of radiotherapy for tumors receiving sequential chemoradiotherapy. In addition, the study permitted a time interval of 4 weeks between the PET scan and the start of treatment to determine if patients were required to undergo another PET scan. Patients undergoing sequential chemoradiotherapy were required another PET scan prior to radiotherapy. Although this interval between the PET scan and the start of treatment may allow for disease progression, it is according to current guidelines (4 weeks) [23].

Similarly, our second hypothesis could not be proven. The inhomogeneous boosting according to FDG uptake did not lower FDG spatial consistency from pre-treatment to post-treatment PET scans when compared to homogeneous boosting or the REG group. In addition to the chemotherapy potentially "pre-selecting" patients and lowering overlap fraction in the REG, there was a great deal of spread in the patient cohort. The overlap fraction ranged from zero to one with the typical inter-quartile range (IQR) covering over $80 \%$ of possible overlap fraction values. This high degree of patient variability was present regardless of treatment group or post-treatment PET SUV threshold investigated, which led to no significant findings between the REG treatment group and the boosted treatment arms, or between the boosted treatment arms.

Contrary to the third hypothesis, residual FDG uptake after treatment in the tumor did not occur in fewer patients in the randomized patients when compared to the non-randomized group. The study found most patients having residual FDG uptake for 3month post-treatment FDG-PET scans. The $\mathrm{SUV}_{\max }$ of the aorta has been used in literature for defining residual disease in NSCLC patients receiving radiation therapy $[15,21]$. In our study, the use of the aorta PET SUV max $_{\operatorname{mielded}}$ only two tumors to be at background levels post-treatment. This may imply that treatment did not reduce tumor SUV below background, or the post-treatment scan represented inflammation, instead of residual disease. The study required patients who had larger tumors $(>4 \mathrm{~cm}$ diameter), and higher SUV $(>5)$. The larger tumors had a greater tumor volume on average in the PET-boost trial REG (207 cc vs. $117 \mathrm{cc}$ ) and a higher pre-treatment SUV on average (18 vs. 10) in comparison to metabolically resistant tumors in Aerts et al. [15]. However, almost all of the patients were PERCIST PET responders with a decrease of greater than 30\% [24]. An alternative explanation may be related to the aorta $S_{U} V_{\text {max }}$ in our study. Our values were slightly lower in comparison to Aerts et al. [15] (2.6 vs. 2.9 SUV), which could be a consequence of the treatment scheme (sequential vs. concurrent chemotherapy) [25]. While no significant differences were found in the population of tumor or aorta PET values in the two major centers of the trial (NKI-31 pts., MAASTRO-30 pts.), differences may have existed in scanner and reconstruction methods between the time of the study by Aerts et al. [15] and the closing of the PET-boost trial (10 year difference). Nevertheless, on average, the post-treatment tumor GTV had a higher SUV $\max$ (4.8) than the aorta found in our study (2.6). However, it should be noted the average post-treatment GTV SUV max $_{\max }$ of patients with residual metabolic uptake was lower than the average GTV SUV $\max$ (6.9) of patients with residual metabolic uptake in Aerts et al. [15].

Future dose boosting or redistribution studies may potentially want to investigate additional time points, as well as alternative options for identification of surrogates of residual metabolic activity. Using a PERCIST based 30\% threshold in the PET-boost trial for response criteria resulted in all, but six patients to display more than a $30 \%$ decrease from pre-treatment to post-treatment $S_{U} V_{\max }$ 
[24]. Similarly, for a subset of the patients $(n=52)$, using the liver (mean $\pm 2 \mathrm{std}$ ) yielded $92 \%$ patients who had residual tumor values above background [24]. While additional metrics such as SUV $_{\text {peak }}$ may be more reliable than $S_{U V} V_{\max }$, they were highly correlated to one another $(R=0.95)$. Exploring other possible metrics (PERCIST, absolute SUV, other organs) involved validating the metric as a surrogate of residual of metabolic activity, while the aorta SUV $_{\text {max }}$ had already been associated in NSCLC for identifying tumor residual metabolic activity $[15,21]$.

Lung inflammation was a common occurrence in the study, being confirmed by a nuclear medicine physician in $73 \%$ (60 patients) of the study patient population. In 30 patients, the post-treatment GTV was adjusted to exclude lung inflammation. The discernment was non-trivial with a comparable SUV for inflammation (4.9 SUV), indicated by the presence of radiation induced pneumonitis, to the post-treatment tumor (4.8 SUV) $[26,27]$. As the nuclear medicine physician was instructed to be conservative in the discernment of tumor and inflammation, this inevitably led to inflammation confounding the analysis in at least a few, complex cases (6/30 patients).

Several factors may have contributed the elevated inflammation rate in the PET-boost trial, in comparison to Aerts et al. [15], despite the same imaging time point of 3 months post-treatment. The study included larger primary tumors leading to increased

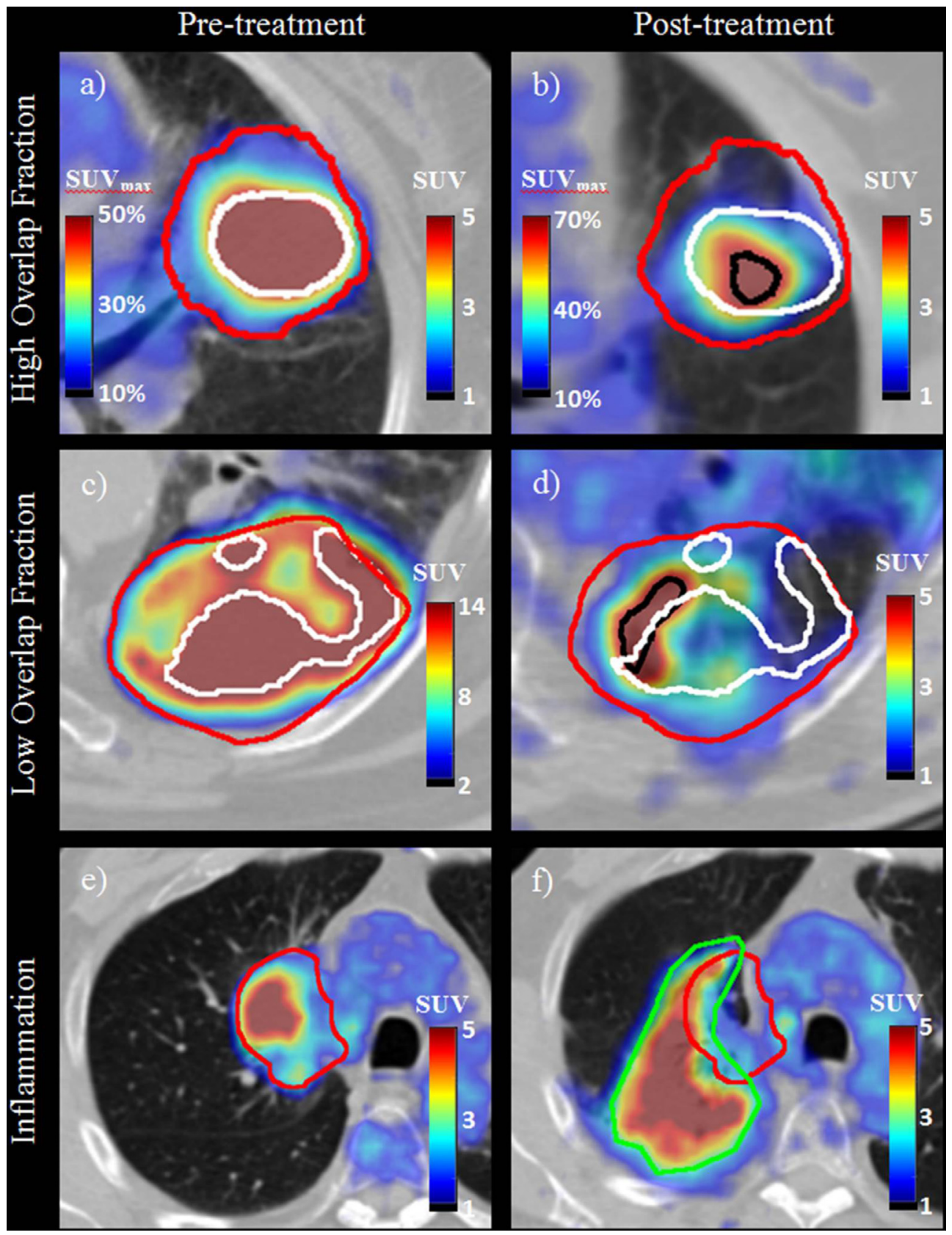

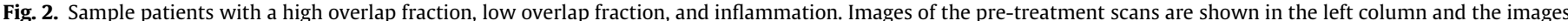

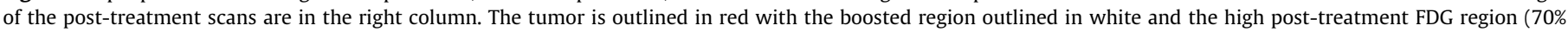

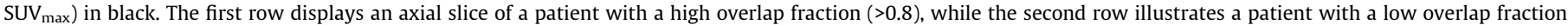
$(<0.2)$. The last row demonstrates the high levels of inflammation seen in the patient cohort with the nuclear medicine physician assisted correction outlined in green. 
a)

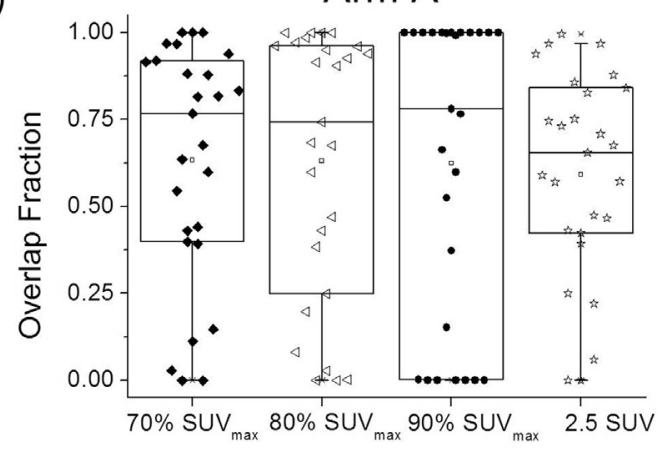

b)

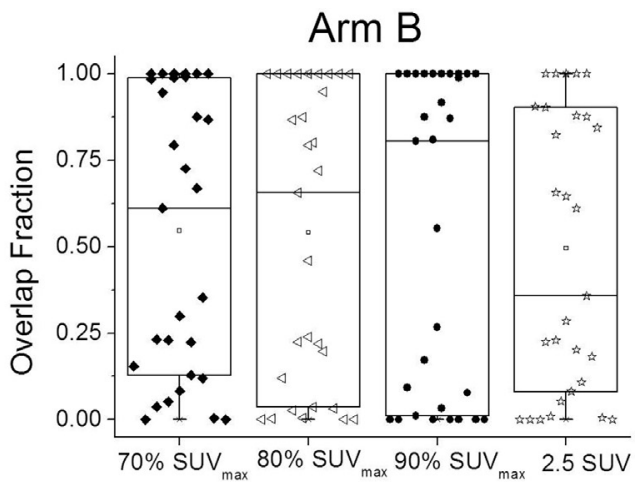

c)

\section{REG}

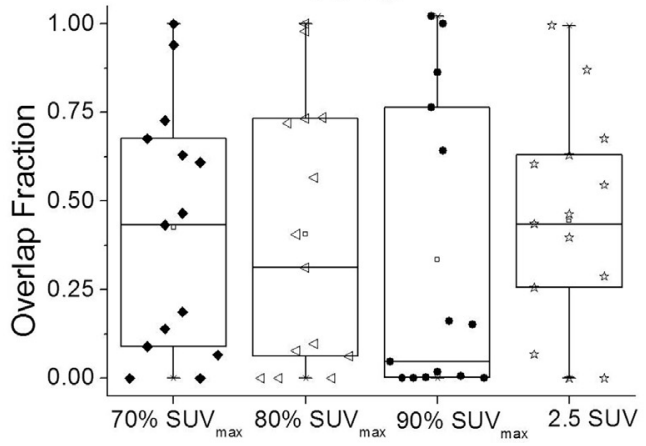

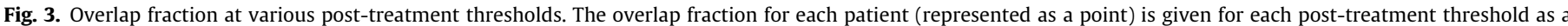

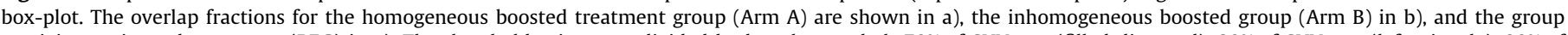

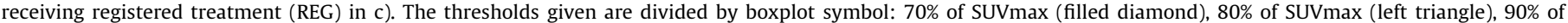
SUVmax (filled circle), and 2.5 SUV (star).

Table 2

Overlap fraction p-values of comparisons between treatment groups.

\begin{tabular}{|c|c|c|c|c|}
\hline \multirow[t]{2}{*}{ Overlap Threshold } & \multicolumn{4}{|c|}{ Comparison between Treatment Groups } \\
\hline & Arm A vs Arm B & Arm A vs REG & Arm B vs REG & Arm A, B vs REG \\
\hline $70 \% \mathrm{SUV}_{\max }$ & 0.68 & 0.10 & 0.28 & 0.14 \\
\hline $80 \% \mathrm{SUV}_{\max }$ & 0.76 & 0.09 & 0.22 & 0.11 \\
\hline $90 \% \mathrm{SUV}_{\max }$ & 0.61 & 0.15 & 0.23 & 0.15 \\
\hline 2.5 SUV & 0.61 & 0.16 & 0.64 & 0.31 \\
\hline
\end{tabular}

dose to the lung. This may have affected multiple dose metrics associated with radiation pneumonitis such as MLD, the volume receiving $\geq 13 \mathrm{~Gy}$ (V13Gy), and the volume receiving $\geq 5 \mathrm{~Gy}$ (V5Gy) [28,29]. The larger tumors were also known to obstruct central airways and cause post-obstructive inflammation of lung tissue. The study primarily applied concurrent rather than sequential chemoradiotherapy in $68 \%$ of cases, which while being associated with increased survival, has greater acute toxicity $[1,30,31]$. There was also a difference in radiotherapy scheme as the work of Aerts et al. [15], where patients were treated up to a maximal dose of 79.2 Gy using twice a day delivery, 5 days per week treatment, as opposed to the $66 \mathrm{~Gy}$ in 24 fractions of the PET-boost trial.

Future studies may attempt to avoid the effects of inflammation. One possible solution is by performing dual time point imaging of FDG, where inflammation stabilizes at an earlier time point than the tumor, permitting separation of inflammation from disease [32,33]. Another potential solution is changing the time point of imaging post-treatment. A study by Shusharina et al. [11] demonstrated that overlap fractions in patients with recurring lung cancer had higher overlap fractions at 10 days after treatment in comparison to 3 months post-treatment, with even lower overlap fractions occurring at 6 months post-treatment. In addition, metabolic tumor activity and volume may change during treatment, in which patients may benefit from boosting on mid-treatment residual FDG uptake, instead of boosting on the pre-treatment FDG uptake $[13,34]$. Future studies may also want to explore the possibility of other tracers for dose redistribution purposes that may be less sensitive to inflammation, but still have an association to resistant disease, such as hypoxia or proliferation markers [35-37].

As opposed to our hypotheses, the PET-boost trial demonstrated that boosting to FDG avid areas did not lower spatial consistency of high uptake FDG regions from pre-treatment to post-treatment values, as there were no significant differences between boosting arms in comparison to the registered patients. However, the imaging time point of the study following treatment ( 3 months) was associated with a high incidence of normal tissue inflammation. Future studies utilizing concurrent chemoradiotherapy, a higher dose per fraction, and/or a higher total dose should consider alternative imaging time points for potential boosting and for measuring spatial consistency after treatment.

\section{Conflict of interest}

The corresponding author is responsible for all contact with the journal on behalf of the authors through the process submission, 
revisions, and approval of proofs. As such, the corresponding author delivered the final version of the manuscript prior to submission to all collaborating co-authors. The co-authors were required to specify any conflicts of interest associated with the submission. On behalf of the authors, we would like to confirm to the best of our knowledge, there were no conflicts of interest with this manuscript. Furthermore, the author list and order has been deliberated based on the criteria of the journal and approved by all authors.

\section{Acknowledgements}

This research was supported by the European Commission, 7th Framework Project Grant Agreement nr. 257144, ARTFORCE project; and the Dutch Cancer Society (project number 2010-4675). The sponsors had no involvement in study design, collection, analysis, or in the interpretation of the data. In addition, the authors would like to recognize Marianne Camille Aznar (Copenhagen), Gilles Defraene (Leuven), Aniek Even (Maastricht), and Maddalena Rossi (Amsterdam) for their efforts in the process of data collecting and transfer.

\section{References}

[1] Aupérin A, Le Péchoux C, Rolland E, Curran WJ, Furuse K, Fournel P, et al. N auperin concurrent meta: meta-analysis of concomitant versus sequential radiochemotherapy in locally advanced non-small-cell lung cancer. JCO 2010;28(13):2181-90. Available from: http://jco.ascopubs.org/content/28/13 2181.abstract.

[2] van Diessen JNA, Chen C, van den Heuvel MM, Belderbos JSA, Sonke J-J. Differential analysis of local and regional failure in locally advanced non-small cell lung cancer patients treated with concurrent chemoradiotherapy. Radiotherapy and Oncology 2016 Aug;118(3):447-52.

[3] Kong F-M, Ten Haken RK, Schipper MJ, Sullivan M, Chen M, Lopez C, et al. Highdose radiation improved local tumor control and overall survival in patients with inoperable/unresectable non-small-cell lung cancer: long-term results of a radiation dose escalation study. International Journal of Radiation Oncology Biology Physics 2005:63(2):324-33.

[4] Schytte T, Nielsen TB, Brink C, Hansen O. Pattern of loco-regional failure after definitive radiotherapy for non-small cell lung cancer. Acta Oncol (Madr) 2014;53(3):336-41.

[5] Belderbos JS, Heemsbergen WD, De Jaeger K, Baas P, Lebesque JV. Final results of a Phase I/II dose escalation trial in non-small-cell lung cancer using threedimensional conformal radiotherapy. International Journal of Radiation Oncology Biology Physics 2006:66(1):126-34.

[6] Bradley JD, Paulus R, Komaki R, Masters G, Blumenschein G, Schild S, et al Standard-dose versus high-dose conformal radiotherapy with concurrent and consolidation carboplatin plus paclitaxel with or without cetuximab for patients with stage IIIA or IIIB non-small-cell lung cancer (RTOG 0617): A randomised, two-by-two factorial p. Lancet Oncology 2015;16(2):187-99.

[7] Ghafoori P, Marks LB, Vujaskovic Z, Kelsey CR. Radiation-induced lung injury. Assessment, management, and prevention. Oncology 2008;22(1):33-7.

[8] Kong FM, Ritter T, Quint DJ, Senan S, Gaspar LE, Komaki RU, et al. Consideration of dose limits for organs at risk of thoracic radiotherapy: atlas for lung, proximal bronchial tree, esophagus, spinal cord, ribs, and brachial plexus. International Journal of Radiation Oncology Biology Physics 2011;81(5):1442-57.

[9] Nishimura S, Takeda A, Sanuki N, Ishikura S, Oku Y, Aoki Y, et al. Toxicities of organs at risk in the mediastinal and hilar regions following stereotactic body radiotherapy for centrally located lung tumors. J Thorac Oncol 2014;9 (9):1370-6. Available from: http://www.ncbi.nlm.nih.gov/pubmed/25122433.

[10] Søren M. Bentzen. Dose painting and theragnostic imaging: towards the prescription, planning and delivery of biologically targeted dose distributions in external beam radiation oncology. In: Cancer. 2008. p. 1894-907.

[11] Shusharina N, Cho J, Sharp GC, Choi NC. Correlation of 18F-FDG avid volumes on pre-radiation therapy and post-radiation therapy FDG PET scans in recurrent lung cancer. International Journal of Radiation Oncology Biology Physics 2014;89(1):137-44.

[12] Aerts HJWL, Bussink J, Oyen WJG, van Elmpt W, Folgering AM, Emans D, et al. Identification of residual metabolic-active areas within NSCLC tumours using a pre-radiotherapy FDG-PET-CT scan: a prospective validation. Lung Cancer 2012;75(1):73-6.

[13] Kong F-M, Ten Haken RK, Schipper M, Frey KA, Hayman J, Gross M, et al. Effect of midtreatment PET/CT-adapted radiation therapy with concurrent chemotherapy in patients with locally advanced non-small-cell lung cancer. JAMA Oncol 2017.

[14] Van Elmpt W, De Ruysscher D, Van Der Salm A, Lakeman A, Van Der Stoep J, Emans D, et al. The PET-boost randomised phase II dose-escalation trial in nonsmall cell lung cancer. Radiotherapy and Oncology 2012;104(1):67-71. https://doi.org/10.1016/j.radonc.2012.03.005.
[15] Aerts HJWL, van Baardwijk AAW, Petit SF, Offermann C, van Loon J, Houben R, et al. Identification of residual metabolic-active areas within individual NSCLC tumours using a pre-radiotherapy 18Fluorodeoxyglucose-PET-CT scan. Radiotherapy and Oncology 2009;91(3):386-92. https://doi.org/10.1016/i. radonc.2009.03.006.

[16] Boellaard R, Oyen WJG, Hoekstra CJ, Hoekstra OS, Visser EP, Willemsen AT, et al. The Netherlands protocol for standardisation and quantification of FDG whole body PET studies in multi-centre trials. European Journal of Nuclear Medicine and Molecular Imaging 2008;35(12):2320-33.

[17] van Baardwijk A, Bosmans G, Dekker A, van Kroonenburgh M, Boersma L, Wanders S, et al. Time trends in the maximal uptake of FDG on PET scan during thoracic radiotherapy. A prospective study in locally advanced nonsmall cell lung cancer (NSCLC) patients. Radiotherapy and Oncology 2007;82 (2): $145-52$.

[18] Borst GR, Belderbos JS, Boellaard R, Comans EFI, De Jaeger K, Lammertsma A, et al. Standardised FDG uptake: a prognostic factor for inoperable non-small cell lung cancer. European Journal of Cancer 2005;41(11):1533-41.

[19] van Baardwijk A, Dooms C, van Suylen RJ, Verbeken E, Hochstenbag M, DehingOberije C, et al. The maximum uptake of 18F-deoxyglucose on positron emission tomography scan correlates with survival, hypoxia inducible factor$1 \alpha$ and GLUT-1 in non-small cell lung cancer. European Journal of Cancer 2007;43(9):1392-8.

[20] Aerts HJWL, Bosmans G, van Baardwijk AAW, Dekker ALAJ, Oellers MC, Lambin P, et al. Stability of 18F-Deoxyglucose Uptake Locations Within Tumor During Radiotherapy for NSCLC: A Prospective Study. International Journal of Radiation Oncology Biology Physics 2008:71(5):1402-7.

[21] Mac Manus MP, Hicks RJ, Matthews JP, Wirth A, Rischin D, Ball DL. Metabolic (FDG-PET) response after radical radiotherapy/chemoradiotherapy for nonsmall cell lung cancer correlates with patterns of failure. Lung Cancer 2005;49 (1):95-108.

[22] Calais J, Thureau S, Dubray B, Modzelewski R, Thiberville L, Gardin I, et al. Areas of high 18F-FDG uptake on preradiotherapy PET/CT identify preferential sites of local relapse after chemoradiotherapy for non-small cell lung cancer. Journal of Nuclear Medicine 2015;56(2):196-203.

[23] Konert T, Vogel W, MacManus MP, Nestle U, Belderbos J, Grégoire V, et al. PET/ CT imaging for target volume delineation in curative intent radiotherapy of non-small cell lung cancer: IAEA consensus report 2014. Radiotherapy and Oncology 2015;116(1):27-34.

[24] Wahl RL, Jacene H, Kasamon Y, Lodge MA. From RECIST to PERCIST: evolving considerations for PET response criteria in solid tumors. Journal of Nuclear Medicine 2009;50(5):122S-50S.

[25] Vera P, Ouvrier MJ, Hapdey S, Thillays M, Pesquet AS, Diologent B, et al. Does chemotherapy influence the quantification of SUV when contrast-enhanced CT is used in PET/CT in lymphoma? European Journal of Nuclear Medicine and Molecular Imaging 2007;34(12):1943-52.

[26] Mac Manus MP, Ding Z, Hogg A, Herschtal A, Binns D, Ball DL, et al. Association between pulmonary uptake of fluorodeoxyglucose detected by positron emission tomography scanning after radiation therapy for non-small-cell lung cancer and radiation pneumonitis. International Journal of Radiation Oncology Biology Physics 2011;80(5):1365-71.

[27] Pastis NJ, Greer TJ, Tanner NT, Wahlquist AE, Gordon LL, Sharma AK, et al. Assessing the usefulness of $18 \mathrm{~F}$-fluorodeoxyglucose PET-CT scan after stereotactic body radiotherapy for early-stage non-small cell lung cancer. Chest 2014;146(2):406-11. Available from: http://www.ncbi.nlm.nih.gov/ pubmed/24577678.

[28] Seppenwoolde Y, Lebesque JV, de Jaeger K, Belderbos JSA, Boersma LJ, Schilstra $\mathrm{C}$, et al. Comparing different NTCP models that predict the incidence of radiation pneumonitis. Normal tissue complication probability. International Journal of Radiation Oncology Biology Physics 2003;55(3):724-35. Available from: http://www.ncbi.nlm.nih.gov/pubmed/12573760.

[29] Ong CL, Palma D, Verbakel WFAR, Slotman BJ, Senan S. Treatment of large stage I-II lung tumors using stereotactic body radiotherapy (SBRT): Planning considerations and early toxicity. Radiotherapy and Oncology 2010;97 (3):431-6.

[30] Zatloukal P, Petruzelka L, Zemanova M, Havel L, Janku F, Judas L, et al. Concurrent versus sequential chemoradiotherapy with cisplatin and vinorelbine in locally advanced non-small cell lung cancer: a randomized study. Lung Cancer 2004;46(1):87-98.

[31] Curran WJ, Paulus R, Langer CJ, Komaki R, Lee JS, Hauser S, et al. Sequential vs concurrent chemoradiation for stage iii non-small cell lung cancer: Randomized phase III trial RTOG 9410. Journal of the National Cancer Institute 2011;103(19):1452-60.

[32] Zhuang H, Pourdehnad M, Lambright ES, Yamamoto AJ, Lanuti M, Li P, et al. Dual time point $18 \mathrm{~F}-\mathrm{FDG}$ PET imaging for differentiating malignant from inflammatory processes. Journal of Nuclear Medicine 2001;42(9):1412-7. Available from: http://jnm.snmjournals.org/content/42/9/1412.long.

[33] Kaneko K, Sadashima S, Irie K, Hayashi A, Masunari S, Yoshida T, et al. Assessment of FDG retention differences between the FDG-avid benign pulmonary lesion and primary lung cancer using dual-time-point FDG-PET imaging. Annals of Nuclear Medicine 2013;27(4):392-9. https://doi.org/ 10.1007/s12149-013-0698-4

[34] Feng M, Kong FM, Gross M, Fernando S, Hayman JA, Ten Haken RK. Using fluorodeoxyglucose positron emission tomography to assess tumor volume during radiotherapy for non-small-cell lung cancer and its potential impact on adaptive dose escalation and normal tissue sparing. International Journal of Radiation Oncology Biology Physics 2009;73(4):1228-34. 
[35] Peeters SGJA, Zegers CML, Yaromina A, Van Elmpt W, Dubois L, Lambin P. Current preclinical and clinical applications of hypoxia PET imaging using 2nitroimidazoles. Q J Nucl Med Mol Imaging 2015;59(1):39-57.

[36] Thorwarth D, Eschmann SM, Paulsen F, Alber M. Hypoxia dose painting by numbers: a planning study. International Journal of Radiation Oncology Biology Physics 2007;68(1):291-300.
[37] Everitt S, Ball D, Hicks RJ, Callahan J, Plumridge N, Trinh J, et al. Prospective study of serial imaging comparing fluorodeoxyglucose positron emission tomography (PET) and fluorothymidine PET during radical chemoradiation for non-small cell lung cancer: reduction of detectable proliferation associated with worse survival. International Journal of Radiation Oncology Biology Physics 2017;99(4):947-55. 